\title{
Preparation of nano-gypsum from anhydrite nanoparticles Strongly increased Vickers hardness and formation of calcium sulfate nano-needles
}

\author{
Journal Article \\ Author(s): \\ Osterwalder, Neil; Loher, Stefan; Grass, Robert N.; Brunner, Tobias J.; Halim, Samuel C.; Limbach, Ludwig; Stark, Wendelin J. \\ Publication date: \\ 2007 \\ Permanent link: \\ https://doi.org/10.3929/ethz-b-000005765 \\ Rights / license: \\ In Copyright - Non-Commercial Use Permitted \\ Originally published in: \\ Journal of Nanoparticle Research 9(2), https://doi.org/10.1007/s11051-006-9149-7
}




\title{
Preparation of nano-gypsum from anhydrite nanoparticles: Strongly increased Vickers hardness and formation of calcium sulfate nano-needles
}

\author{
Neil Osterwalder, Stefan Loher, Robert N. Grass, Tobias J. Brunner, Ludwig K. Limbach, Samuel C. \\ Halim and Wendelin J. Stark* \\ Department of Chemistry and Applied Biosciences, Institute for Chemical and Bioengineering, ETH Zurich, CH- \\ 8093, Zurich, Switzerland; *Author for correspondence (Fax: +41-44-6331083; E-mail: wendelin.stark@ \\ chem.ethz.ch)
}

Received 12 June 2006; accepted in revised form 26 July 2006

Key words: Vickers hardness, gypsum, nanoparticles, compaction, construction material, nano-needle, nanocomposites

\begin{abstract}
The preparation of calcium sulfate by flame synthesis resulted in the continuous production of anhydrite nanoparticles of 20-50 $\mathrm{nm}$ size. After compaction and hardening by the addition of water, the anhydrite nanoparticles reacted to nano-gypsum which was confirmed by X-ray diffraction, diffuse reflectance IR spectroscopy and thermal analysis. Mechanical properties were investigated in terms of Vickers hardness and revealed an up to three times higher hardness of nano-gypsum if compared to conventional micronsized construction material. The improved mechanical properties of nano-gypsum could in part be due to the presence of calcium sulfate nano-needles in the nano-gypsum as showed by electron microscopy.
\end{abstract}

\section{Introduction}

Gypsum as one of the oldest known construction materials (Coquard et al., 1994) today accounts for a worldwide production of an estimated 100 mio. metric tons of calcium sulfate for renders, plasters, indoor finishings, retardants for cement, ceramics and medical supplements or implants (Karni \& Karni, 1995; Arikan \& Sobolev, 2002; Harris et al., 2004; Melo et al., 2005; Papageorgiou et al., 2005; Peters et al., 2005; Sievert et al., 2005). It is prepared by heating ground gypsum rock (selenite, alabaster or satin-spar) that results in the loss of crystal water (Olsen, 2004) and yields the active form of gypsum, anhydrite or hemihydrate. Depending on the amount of water added to the activated calcium sulfate, gypsum plasters of different hardness are obtained. The initially formed slurry or paste rapidly sets with only small dimensional changes (Hand, 1997), enabling application as dental plaster where hardening time and final hardness are of major importance (Luebke \& Chan, 1985). The reactivity of the anhydrite could be considerably enhanced by grinding of the starting material or the addition of activators (Coquard et al., 1994). These observations indicated that the mechanical stability of gypsum or other cement materials could be significantly improved by using extremely fine particles. Preliminary investigations by Song et al. (2003) have yielded a colorful variety of particle morphologies using precipitation of calcium sulfate in organic media. Similarly, Kuang et al. (2002) and Rees et al. (1999) produced nano-sized calcium sulfate in water-in-oil microemulsions and obtained spherical nanoparticles of $10-50 \mathrm{~nm}$, 
nanowires or short nanorods but did not investigate the mechanical properties or hardening process of such gypsum material. Since possible applications of nano-anhydrite as a source for nano-gypsum are expected to rapidly require large volume production, we have investigated a suitable modification of the existing aerosol process (Stark and Pratsinis, 2002) for the manufacturing of silica, titania and soot (10 mio. tons/year) to access nano-anhydrite or gypsum. More specifically, $\mathrm{CaSO}_{4}$ nanoparticles were prepared by flame spray synthesis (Madler et al., 2002a; Stark et al., 2002; Johannessen et al., 2004; Stark et al., 2004) and characterized by X-ray diffraction, scanning electron microscopy, thermal analysis and nitrogen adsorption. The mechanical properties of gypsum derived from nano-anhydrite were investigated in terms of Vickers hardness using a microhardness testing device. Electron microscopy of hardened nano-anhydrite revealed the presence of gypsum nano-needles which may account for the increased hardness of such nanostructured construction materials if compared to conventional gypsum.

\section{Experimental}

\section{Powder synthesis}

Nano-anhydrite was synthesized by flame spray synthesis using a precursor containing corresponding calcium and sulfur comprising organic derivatives. $\mathrm{Ca}(\mathrm{OH})_{2}$ (Riedel-Haen, p.a.) was dissolved in 2-ethylhexanoic acid (Soctec, tech., Romania) by heating to $140^{\circ} \mathrm{C}$ for $3 \mathrm{~h}$ resulting in the removal of reaction water and formation of a clear light-yellow 0.5 M calcium 2-ethylhexanoate solution. Prior to synthesis, the liquid was mixed with dimethyl sulfoxide (Acros, 99.7\%) as a sulfur source at a molar ratio of 9:11 and diluted with 50 vol $\%$ xylene. The liquid mixture was fed through a capillary (diameter $0.4 \mathrm{~mm}$ ) and sprayed into a methane (1.13 $1 \mathrm{~min}^{-1}$, Pan Gas, tech)/oxygen (2.4 $1 \mathrm{~min}^{-1}$, Pan Gas, tech) flame using a gearring pump (HNP Mikrosysteme) at a rate of $5 \mathrm{ml} \mathrm{min}{ }^{-1}$. Oxygen $\left(51 \mathrm{~min}^{-1}\right.$, Pan Gas, tech) was used to disperse the liquid leaving the capillary. A stable combustion was achieved by applying a sheath gas (oxygen, $2301 \mathrm{~h}^{-1}$, Pan Gas, tech) through a concentric sinter metal ring. Calibrated mass flow controllers (Brooks) were used to monitor gas flows. The as-formed particles were collected on a glass fibre filter (Whatmann GF/A, $25.7 \mathrm{~cm}$ in diameter), placed on a cylinder mounted above the flame, by the aid of a vacuum pump (Busch). The filtration equipment was preheated to $150^{\circ} \mathrm{C}$ before starting the synthesis of nano-anhydrite in order to avoid condensation of humidity onto the moisture sensitive product (Grass \& Stark, 2005).

\section{Powder analysis}

Transmission electron micrographs (LEO 1530 Gemini, Accelerating voltage $10 \mathrm{kV}$ ) were recorded to investigate the morphology of assynthesized materials. The specific surface area of nano-anhydrite before hardening and nano-gypsum after reaction was measured using nitrogen adsorption on a Tristar (Micromeritics Instruments) at $77 \mathrm{~K}$ according to the BET method. The mean particle diameter $\mathrm{d}_{\mathrm{BET}}$ (Table 1) was calculated from the specific surface area $\left(\mathrm{SSA}_{\mathrm{BET}}\right)$ and the material bulk density $(\rho)$ using the following correlation (Madler et al., 2002b):

$$
d_{\mathrm{BET}}=\frac{6}{\operatorname{SSA}_{\mathrm{BET}} \rho}
$$

The formation of different crystal phases was confirmed by X-ray powder diffraction (XRD, Stoe STADI-P2, Ge monochromator, $\mathrm{CuK}_{\alpha 1}$, PSD detector) and diffuse reflectance Fouriertransformed Infrared spectroscopy measurements (Pike, Diffuse IR unit; Bruker, Tensor 27). The thermal evolution and subsequent crystallization of partially amorphous calcium sulfate was followed quantitatively in a thermo-balance (Linseis TG/STA-PT $1600, \quad 25-500^{\circ} \mathrm{C}, \quad 10^{\circ} \mathrm{C} / \mathrm{min}, \quad$ air $)$

Table 1. Physical properties of nano-anhydrite and reference gypsum powders

\begin{tabular}{lrc}
\hline Sample & $\begin{array}{l}\text { Specific surface } \\
\mathrm{area}^{\mathrm{a}} / \mathrm{m}^{2} \mathrm{~g}^{-1}\end{array}$ & $\begin{array}{l}\text { Mean particle } \\
\text { diameter } \mathrm{d}_{\mathrm{BET}} \mathrm{b} / \mathrm{nm}\end{array}$ \\
\hline $\mathrm{CaSO}_{4}$, flame, (7/3) & 102 & 20 \\
$\mathrm{CaSO}_{4}$, flame, (5/5) & 84 & 24 \\
$\mathrm{CaSO}_{4}$, flame, (3/7) & 56 & 36 \\
Alabaster, ref. & 6 & 340 \\
Gypsum, ref. & 5 & 380 \\
Nano-gypsum, (3/7) & 47 & 43 \\
\hline
\end{tabular}

a Error $\pm 3 \%$.

${ }^{\mathrm{b}}$ Calculated according to Eq. (1), error: $\pm 10 \%$. 
Table 2. Different types of gypsum

\begin{tabular}{ll}
\hline Type of gypsum & Water to powder ratio \\
\hline Type I: Impression plaster & 0.5 \\
Type II: Model plaster & 0.5 \\
Type III: Stone & 0.3 \\
Type IV: High-strength stone & 0.22 \\
\hline
\end{tabular}

coupled to a mass spectrometer (Thermostar, Balzers) for analysis of evolving gases.

\section{Setting of nano gypsum and Vickers hardness}

Prior to hardness measurements, both reference and as-prepared materials were pressed uniaxial to pills of $12.5 \mathrm{~mm}$ diameter by applying $120 \mathrm{MPa}$ during $5 \mathrm{~min}$. The materials were hardened by mixing or soaking with corresponding amounts of water (Table 2) producing different types of plasters that were further analyzed by XRD for phase composition and scanning electron microscopy to assess the morphology. As a reference material, common alabaster (modelling plaster, Boesner, Switzerland) was used. The hardness of materials before or after the hardening reaction was determined by a Vickers micro-hardness test (Wolpert MTX- $\alpha$ ) and evaluated using the following relation:

$$
\mathrm{VHN}=1.854 P / d^{2}
$$

where $P$ denotes the load applied in $\mathrm{kg}$ and $d$ is the indentation diagonal in $\mathrm{mm}$. Further details are given in Kumareson \& Devanarayanan (1992).

\section{Results}

In order to compare conventional alabaster $\left(\mathrm{CaSO}_{4} \cdot 0.15 \mathrm{H}_{2} \mathrm{O}\right.$ as shown by X-ray diffraction) to nano-gypsum derived from anhydrite nanoparticles (Figure 1), the preparation of suitable calcium sulfate nanoparticles was investigated using a series of process conditions during flame spray synthesis. Using relatively slow gas flow rates, i.e. low sheer rates during flame spray synthesis (high liquid to gas flow rate in the spray, Figure 2, (7/3)), resulted in comparably hot flames with slow cool-down (Stark et al., 2001; Madler et al., 2002a; Stark et al., 2002). As a consequence, predominantly calcium oxide was produced
(Figure 2, top trace). Decreasing the liquid to gas ratio during preparation promoted higher sheer rate, faster cool-down, less calcium oxide and resulted in the formation of calcium sulfate anhydrite III (PDF No. 37-184, Figure 2, bottom trace, (3/7); Bushuew et al., 1983). In contrast to earlier detailed investigations of Madler et al. (2002a) on ceria, the specific surface area decreased with the liquid to gas ratio and resulted in smaller primary particles (Table 1). This observation correlates well to the different melting points of $\mathrm{CaO}$ $\left(\mathrm{T}_{\mathrm{m}}=2900^{\circ} \mathrm{C}\right)$ and $\mathrm{CaSO}_{4} \quad\left(\mathrm{~T}_{\mathrm{m}}=1450^{\circ} \mathrm{C}\right)$. Scanning electron micrographs (Figure 1) showed highly agglomerated nanoparticles of $20-50 \mathrm{~nm}$ diameter which was consistent with the surface area equivalent diameter $\mathrm{d}_{\mathrm{BET}}$ (Table 2) calculated according to Eq. (1).

The phase purity of the as-prepared calcium sulfate was investigated by X-ray diffraction and FTIR-spectroscopy (Figures 3 and 4) that confirmed the formation of calcium sulfate and revealed the presence of some carbonate species (Figure 4). The carbonate content was further analyzed quantitatively by differential thermal analysis and resulted in a typical endothermic peak at $700^{\circ} \mathrm{C}$ indicating the decomposition of calcium carbonate as found in earlier preparation on nanolimestone (Huber et al., 2005). A detailed comparison in terms of thermal decomposition of reference materials (alabaster) and as-prepared $\mathrm{CaSO}_{4}$ is shown in Figure 5. In agreement with stoichiometry, alabaster looses more water upon heating while the nano-anhydrite only contained $2-3 \mathrm{wt} \%$ of physisorbed water (Figure 5, mass loss at $100-200^{\circ} \mathrm{C}$; negative DSC peak; $\mathrm{m} / \mathrm{z}=18$ mass spectrometer signal for water $\mathrm{H}_{2} \mathrm{O}$ ). Both materials contained minor amounts of carbonate as quantitatively measured by the small mass loss around $700^{\circ} \mathrm{C}$ and evolution of some carbon dioxide (MS trace, $\mathrm{m} / \mathrm{z}=44$; Huber et al., 2005).

The hardness of gypsum derived from the asprepared nano-anhydrite or conventional alabaster was compared for increasing water to powder ratios (Figure 6). At high water content (type I gypsum), the nanostructured gypsum was about twice as hard as the reference material. At low water content (hard stone gypsum, type IV), a very pronounced increase in hardness of about a factor of three could be observed. We therefore investigated the morphology of these two most different materials using scanning electron microscopy 

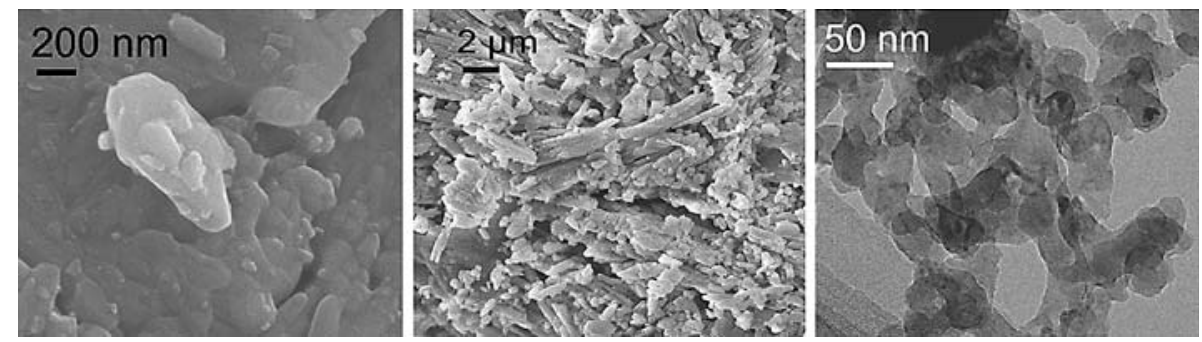

Figure 1. Comparison of alabaster (left as powder and middle after hardening, water to powder ratio: 0.22) and $\mathrm{CaSO}_{4}$ anhydrite nanoparticles after preparation (right).

(Figures 1 and 7). Alabaster consisted of micronsized irregular pieces of calcium sulfate with a relatively small specific surface area (Table 1). The hardening process induced the formation of submicron sized needles upon hardening (Figure 1) while the specific surface area remained largely unaffected (Table 1). Most interestingly, the high specific surface of nano-anhydrite was similarly constant after hardening to nanostructured gypsum (Table 1) while the morphology had drastically changed. Figure 7 shows a fracture surface of hardened nano-anhydrite where the calcium sulfate obviously formed nano-needles with a high aspect ratio.

\section{Discussion}

Traditionally, $\mathrm{CaSO}_{4}$ anhydrite has been prepared by prolonged heating of gypsum rock. The crystal

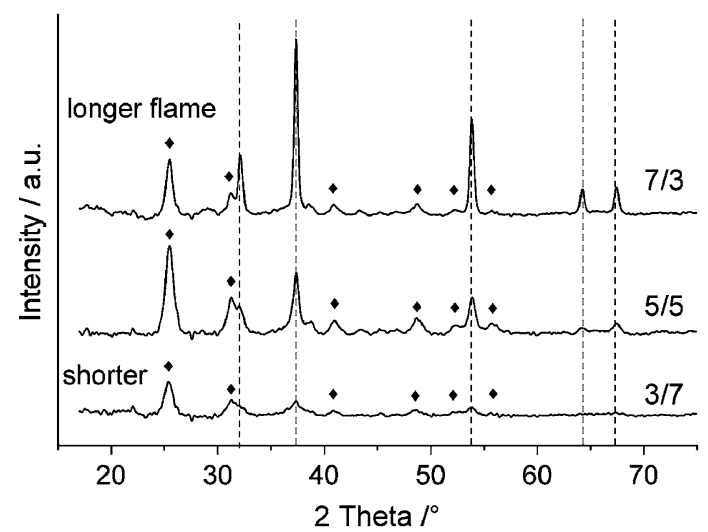

Figure 2. The effects of liquid to gas ratio during production of $\mathrm{CaSO}_{4}$ (diamonds) as shown by X-ray diffraction. Higher temperatures (top trace) promoted the formation of $\mathrm{CaO}$ as an impurity. phase anhydrite III (Figure 3) can be obtained by hydrothermal treatment of gypsum at $180^{\circ} \mathrm{C}$ for $24 \mathrm{~h}$ (Bushuew et al., 1983). Alternatively, using a high temperature process and extremely small particles, the resulting diffusion paths become extremely short and material preparation by flame synthesis can take place in a few milliseconds (Grass et al., 2006). The sensitivity of the calcium sulfate preparation to the synthesis conditions (liquid to gas ratio, Table 1, Figure 2) illustrates how sulfur oxides and carbon dioxide are competing for the reaction with the basic calcium oxide in the off-gas of the flame. The use of very hot and relatively slow flames even promoted the formation of larger calcium oxide rich nanoparticles (Figure 2, top trace). The particles (Table 1, $\mathrm{d}_{\mathrm{BET}}$ : $36 \mathrm{~nm}$ ) formed under these conditions were too large to allow full reaction to calcium sulfate $\left(\mathrm{CaO}+\mathrm{SO}_{3}=\mathrm{CaSO}_{4}\right)$ and X-ray diffraction confirmed that mainly $\mathrm{CaO}$ was formed. In contrast, faster and shorter flames promoted smaller partially amorphous particles (Table 1, $\mathrm{d}_{\mathrm{BET}}$ :

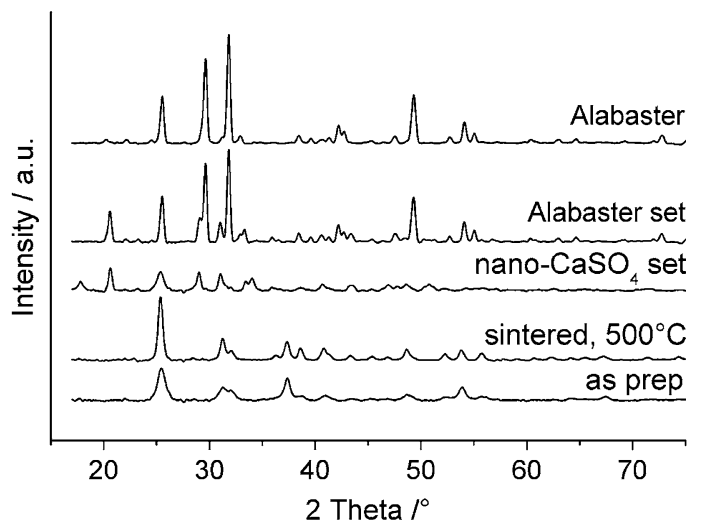

Figure 3. X-ray diffraction pattern of reference alabaster and nano- $\mathrm{CaSO}_{4}$ before and after setting. 


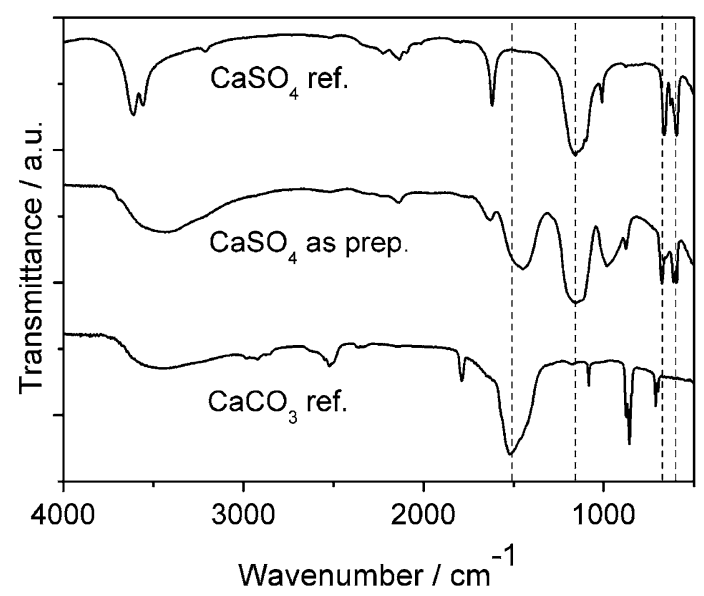

Figure 4. Diffuse reflectance IR spectroscopy of reference alabaster (top), as prepared anhydrite nanoparticles (middle) and $\mathrm{CaCO}_{3}$ reference (bottom). The formation of some carbonate species is evident from signals around $1500 \mathrm{~cm}^{-1}$.

$20 \mathrm{~nm}$ ) that had sufficient time to react with sulfur oxides in the off-gas during the cool-down process. Still, the surface of the anhydrite was covered by carbonate species. Latter was confirmed by surface sensitive FTIR spectroscopy (Figure 4). In terms of mass, the carbonate content was still small and in the range of the carbonate content of the reference alabaster (Figure 5). In order to better illustrate the thermodynamics during anhydrite nanoparticle formation in the flame, a simple
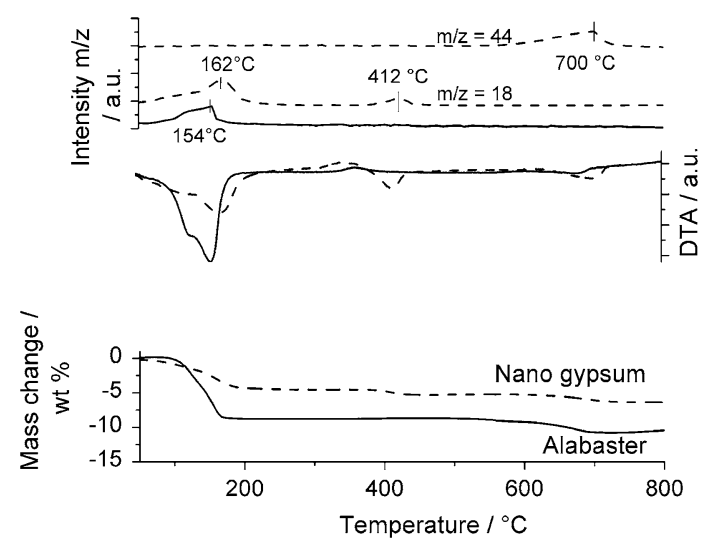

Figure 5. Differential thermal analysis and mass spectroscopy of evolving gases for reference alabaster and $\mathrm{CaSO}_{4}$ nanoparticles upon heating to $800^{\circ} \mathrm{C}$. The release of water $(\mathrm{m} / \mathrm{z}=18)$ or small amounts of carbon dioxide $(\mathrm{m} / \mathrm{z}=44)$ stays in agreement with stoichiometry.

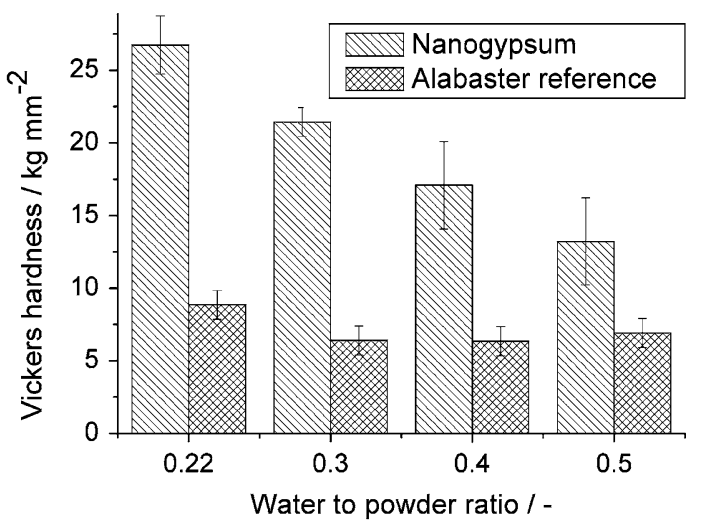

Figure 6. Vickers hardness of nano-gypsum and reference alabaster. Depending on the water to powder ratio, the nanostructured material is up to three times harder.

thermodynamic calculation has been included (Figure 8). The model uses typical temperature profiles in such flame sprays (Arabi-Katbi et al., 2002; Madler et al., 2002a) and the second Ulrich approximation (Sandler, 1999) for the calculation of free energy values. It plots the residence time of the particles in the flame vs. the Gibbs free energy

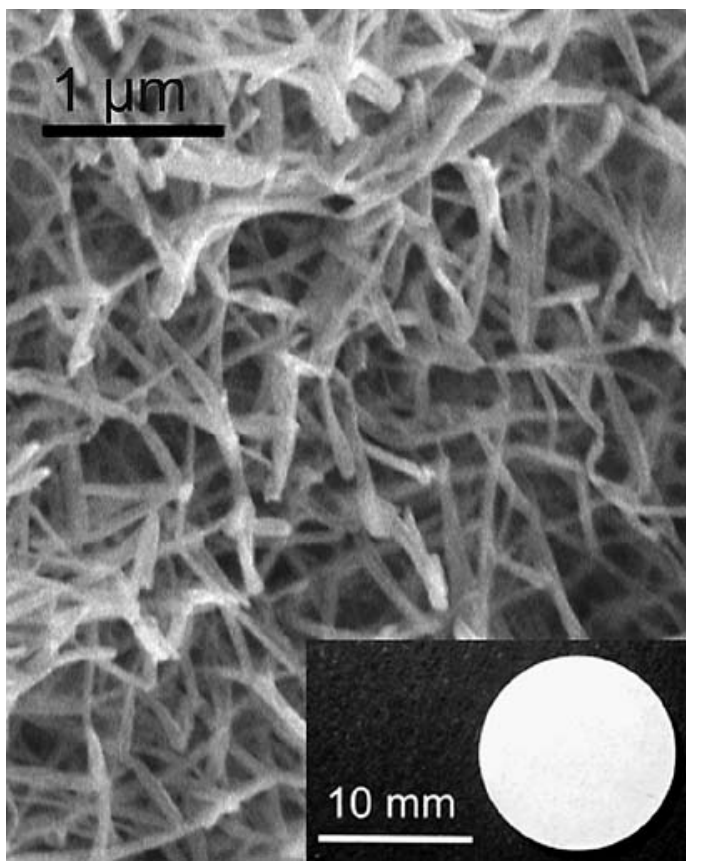

Figure 7. Scanning electron micrograph of nano-gypsum after setting; insert: pressed nano-gypsum pill. The hardening of nano-anhydrite results in the formation of calcium sulfate nano-needles. 


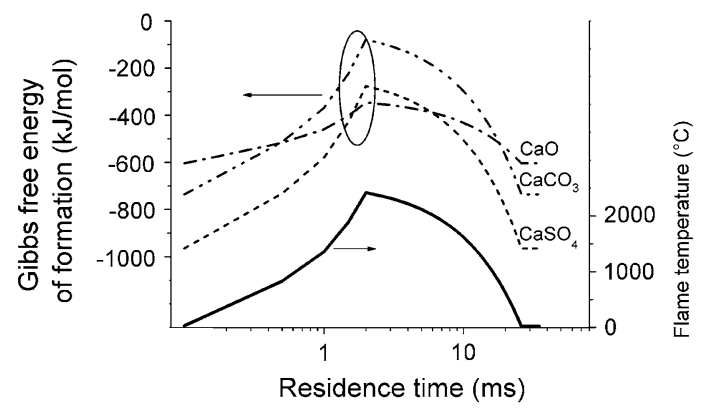

Figure 8. Gibbs free enthalpy of $\mathrm{CaO}, \mathrm{CaSO}_{4}$ and $\mathrm{CaCO}_{3}$ vs. time and temperature gradient in the flame.

of the possible reaction products. Calcium oxide $(\mathrm{CaO})$ is the most stable form at temperatures above $1900^{\circ} \mathrm{C}$. During cooling, $\mathrm{CaSO}_{4}$ and $\mathrm{CaCO}_{3}$ become more favorable and therefore $\mathrm{CaO}$ reacts to the corresponding salts. Below $800^{\circ} \mathrm{C}$, calcium carbonate can be produced, this range of stability agrees with the decomposition profile of $\mathrm{CaCO}_{3}$ (Figure 5, TG pattern). Since sulfur trioxide is a stronger acid than $\mathrm{CO}_{2}$, calcium oxide preferable reacts with $\mathrm{SO}_{3}$ to anhydrite. At very low remaining $\mathrm{SO}_{3}$ concentration, however, the presence of large concentrations of carbon dioxide in the off-gas allow some competition of $\mathrm{SO}_{3}$ and $\mathrm{CO}_{2}$ for the calcium oxide. As a consequence, some carbonate is found on top of the anhydrite as evidenced by the FTIR spectra (Figure 4).

While the most useful properties of anhydrite and gypsum have been applied for a long time, relatively few has been known on the mechanisms inducing specific mechanical properties in these omnipresent materials. The strength of an anhydrite binder depends on the degree of drying and hydration (Sievert et al., 2005). El Hajjouji and Murat (1987) considered pore size as a major factor determining materials properties and correlated the size of the resulting pores to the size of the gypsum crystals in the hardened material. Since the present investigation has used identical preparation procedures and setting on both micron sized reference alabaster and nano-anhydrite, our results are in line with latter study. Similarly, the development of nanocrystalline metals has revealed the favorable influence of small grain size on product hardness (Gleiter, 1989; Meyers et al., 2006). A number of detailed studies on ceramics has corroborated the possible improvement of materials properties by applying nanostructured ceramics (Xu, 2005; Zhan \& Mukherjee, 2005). The present observation of 2-3 times higher Vickers hardness of nano-gypsum if compared to conventional gypsum extends these observation to one of the most frequently used construction materials. While it may only be speculated about the detailed mechanism of this improvement, some suggestions may be given on possible mechanisms. The nano-needle structures observed on the surface of gypsum prepared from nano-anhydrite may be responsible for a stronger entanglement of fibrous gypsum crystallites in this material. Latter would obviously increase the hardness of the bulk material. Similarly, the specific geometry of agglomerated anhydrite nanoparticles with some carbonate impurities may have a pronounced influence on the crystallization of gypsum.

\section{Conclusion}

The present study has shown how the mechanical properties of a construction material may be significantly improved using nanostructured materials. Since nano-anhydrite as a starting material has been difficult to prepare by classical wet-phase chemistry for its high reactivity with water, we have investigated the use of a high-temperature preparation method as an alternative. Application of a suitable flame spray process delivered 20$50 \mathrm{~nm}$ sized anhydrite particles. After compaction and hardening, the resulting gypsum consisted of nano-needles displayed a 2-3 times higher Vickers hardness if compared to conventional micronsized gypsum.

\section{Acknowledgments}

This work was financed by the ETH Zurich. The authors would like to thank Dr. F. Krumeich for transmission electron microscopy and Prof. L. J. Gaukler for SEM measuring time.

\section{References}

Arabi-Katbi O.I., S.E. Pratsinis \& P.W. Morrison, 2002. In situ infrared measurements on $\mathrm{TiO}_{2}$ flames: Gas and particle concentrations. AIChE J. 48(1), 59-68. 
Arikan M. \& K. Sobolev, 2002. The optimization of gypsumbased composite material. Cem. Concr. Res. 32, 1725-1728.

Bushuew N., B.M. Maselnnikow \& V.M. Borisov, 1983. Phase transformations in the dehydration of $\mathrm{CaSO}_{4} 2 \cdot \mathrm{H}_{2} \mathrm{O}$. Russ. J. Inorg. Chem. 28, 1404.

Coquard P., R. Boistelle, L. Amathieu \& P. Barriac, 1994. Hardness, elasticity modulus and flexion strength of dry set plaster. J. Mater. Sci. 29, 4611-4617.

Gleiter H., 1989. Nanocrystalline materials. Progr. Mater. Sci. 33(4), 223-315.

Grass R.N. \& W.J. Stark, 2005. Flame synthesis of calcium-, strontium-, barium fluoride nanoparticles and sodium chloride. Chem. Commun. 14, 1767-1769.

Grass R.N., S. Tsantillis \& S.E. Pratsinis, 2006. Design of hightemperature, gas-phase synthesis of hard or soft $\mathrm{TiO}_{2}$ agglomerates. AIChE J. 52, 1318-1325.

Hajjouji A.E. \& M. Murat, 1987. Strength development and hydrate formation rate, investigation on anhydrite binders. Cem. Concr. Res. 17, 814-822.

Hand R.J., 1997. Calcium sulphate hydrates: A review. Br. Ceram. Trans. 96(3), 116-120.

Harris P.E., S. Hoyer, T.J. Lindquist \& C.M. Stanford, 2004. Alterations of surface hardness with gypsum die hardeners. J. Prost. Dent. 92(July), 35-38.

Huber M., W.J. Stark, S. Loher, M. Maciejewski, F. Krumeich \& A. Baiker, 2005. Flame synthesis of calcium carbonate nanoparticles. Chem. Commun. 648-650.

Johannessen T., J.R. Jenson, M. Mosleh, J. Johansen, U. Quaade \& H. Livbjerg, 2004. Flame synthesis of nanoparticles - Applications in catalysis and product/process engineering. Chem. Eng. Res. \& Design. 82(A11), 1444-1452.

Karni J. \& E. Karni, 1995. Gypsum in construction: Origin and properties. Mater. Struct. 28, 92-100.

Kuang D.B., A.W. Xu, Y.P. Fang, H.D. Ou \& H.Q. Liu, 2002. Preparation of inorganic salts $\left(\mathrm{CaCO}_{3}, \mathrm{BaCO}_{3}, \mathrm{CaSO}_{4}\right)$ nanowires in the Triton $\mathrm{X}-100 /$ cyclohexane/water reverse micelles. J. Crys. Growth. 244(3-4), 379-383.

Kumareson P. \& S. Devanarayanan, 1992. Gypsum crystals grown in silica gel in the presence of citric acid as additive: A study on microhardness. J. Mater. Sci. Lett. 11, 150-151.

Luebke R.J. \& K.C. Chan, 1985. Effect of microwave oven drying on surface hardness of dental gypsum products. J. Prosthet. Dent. 54(3), 431-435.

Madler L., H.K. Kammler, R. Mueller \& S.E. Pratsinis, 2002a. Controlled synthesis of nanostructured particles by flame spray pyrolysis. J. Aerosol Sci. 33(2), 369-389.

Madler L., W.J. Stark \& S.E. Pratsinis, 2002b. Flame-made ceria nanoparticles. J. Mater. Res. 17(6), 1356-1362.
Melo L.G.N., M.J.H. Nagata, A.F. Bosco, L.L.G. Ribeiro \& C.M. Leite, 2005. Bone healing in surgically created defects treated with either bioactive glass particles, a calcium sulfate barrier, or a combination of both materials. Clin. Oral Impl. Res. 16, 683-691.

Meyers M.A., A. Mishra \& D.J. Benson, 2006. Mechanical properties of nanocrystalline materials. Progr. Mater. Sci. 51(4), 427-556.

Olsen D.W., 2004. Mineral Commodity Summaries. U.S. Geological Survey, pp. 76-77.

Papageorgiou A., G. Tzouvalas \& S. Tsimas, 2005. Use of inorganic setting retarders in cement industry. Cem. Concr. Res. 27, 183-189.

Peters C.P., J.L. Hines, K.N. Bachus, M.A. Craig \& R.D. Bloebaum, 2005. Biological effects of calcium sulfate as bone graft substitute in ovine metaphyseal defects. J. Biomed. Mater. Res. A. 76(3), 456-462.

Rees G.D., R. Evans-Gowing, S.J. Hammond \& B.H. Robinson, 1999. Formation and morphology of calcium sulfate nanoparticles and nanowires in water-in-oil microemulsions. Langmuir 15(6), 1993-2002.

Sandler S.I., 1999 Chemical and Engineering Thermodynamics. New York: John Wiley \& Sons.

Sievert T., W. Wolter \& N.B. Singh, 2005. Hydration of anhydrite of gypsum $\left(\mathrm{CaSO}_{4}\right.$.II) in a ball mill. Cem. Concr. Res. 35, 623-630.

Song X.Y., S.X. Sun, W.L. Fan \& H.Y. Yu, 2003. Preparation of different morphologies of calcium sulfate in organic media. J. Mater. Chem. 13(7), 1817-1821.

Stark W.J., A. Baiker \& S.E. Pratsinis, 2002. Nanoparticle opportunities: Pilot-scale flame synthesis of vanadia/titania catalysts. Part. Part. Syst. Char. 19(5), 306-311.

Stark W.J., L. Mädler \& S.E. Pratsinis, 2004. Metal oxides prepared by flame pyrolysis, WO2004/005184 2004.

Stark W.J. \& S.E. Pratsinis, 2002. Aerosol flame reactors for manufacture of nanoparticles. Powder Technol. 126(2), 103108.

Stark W.J., K. Wegner, S.E. Pratsinis \& A. Baiker, 2001. Flame aerosol synthesis of vanadia-titania nanoparticles: Structural and catalytic properties in the selective catalytic reduction of $\mathrm{NO}$ by $\mathrm{NH}_{3}$. J. Catal. 197(1), 182-191.

$\mathrm{Xu}$ C.H., 2005. Research and application of ceramic die materials.. Rare Metal Mater. Eng. 34, 262-265.

Zhan G.D. \& A.K. Mukherjee, 2005. Processing and characterization of nanoceramic composites with interesting structural and functional properties. Rev. Adv. Mater. Sci. 10(3), 185-196. 